\title{
Motorcycle accident modelling for the formulation of motorist safety action programs in Kupang City
}

\author{
Margareth E. Bolla ${ }^{1, *}$, Tri Mardiyati $\mathrm{Sir}^{2}$, and Putri D. K. Djahamouw ${ }^{3}$ \\ ${ }^{1}$ Doctoral Study Program of Civil Engineering, Faculty of Engineering, Brawijaya University, Malang, Indonesia \\ ${ }^{2}$ Civil Engineering Department, Faculty of Science and Engineering, Nusa Cendana University, Kupang, Indonesia \\ ${ }^{3}$ Magister Study Program of Civil Engineering, Faculty of Engineering, Brawijaya University, Malang, Indonesia
}

\begin{abstract}
Kupang city had to deal with transport safety issues where the total number of traffic accidents in 2017 increased by $51.05 \%$ compared to 2011 . This study aims to describe and analyze the factors that affect motorcycle accidents through modelling by the method of Generalized Linear Models with Genstat and SPSS programm. Based on the results of the police report data summary, accidents most often occur on Sunday (15.95\%); the time span at 18:00 to $23: 59 \mathrm{pm}$ (45.94\%); type of hit the front (35.68\%); victims died (12.19\%), male sex $(80.71 \%)$; age range 18-25 years (37.20\%); with the level of education at the level of Higher Education (42.38\%); worked in the private sector $(37.75 \%)$; do not have a driver's license $(75.43 \%)$. The results of the analysis of survey data obtained equation modelling accident MCA $=0,0006713^{*}$ Flow $0.000275^{*} \exp [0.2144$ LaneWidth - ShoulderWidth_Sidewalk 1.952 - 2.026 MedianRoad + 0.2139 Speed +0.0513 Access]. Modelling results showed that the addition of total lane width decrease the number of motorcycle accidents by $10 \%$ per year, pavement by $6 \%$ per year, median by $13 \%$ per year, traffic flow by $3 \%$ per year, speed by $14 \%$ per year, access road by $2 \%$ per year. It is therefore recommended a program of action in the form of additional elements of the road medians and pavement on a road segment that the accident rate can be reduced.
\end{abstract}

\section{Introduction}

Community needs for efficient and affordable transportation modes have resulted in a growing number of motorbikes in Indonesia. The use of motorcycles in Indonesia is very popular because the price is relatively cheap, so it can be reached by most people because of the use of fuel and operational costs that are quite economical. The rapid growth of motorized vehicles is not followed by the growth of road infrastructure and good traffic procedures by motorists, causing negative impacts such as accidents and air pollution. According to data from the Kupang City Traffic Unit (SATLANTAS), the number of traffic accidents (Lakalantas) in 2017 increased by $51.05 \%$ compared to 2011 . The number of victims due to traffic accidents in 2017 also increased by $46.49 \%$ compared to 2011.

This research is part of an effort to find solutions to reduce motorcycle accidents that continue to increase every year in the City of Kupang. By knowing the significance of these accident factors, an action program can be prepared which is expected to be more effective and on target in reducing the number of motorcycle accidents through modelling by the method of Generalized Linear Models with Genstat and SPSS programm. This research is limited by several things as follows:

1. Identification of the road accidents causes studied only covers traffic factors, namely the flow, speed and composition of the vehicle, and the road geometric factors.

2. The area studied is the arterial road network and collectors in the administrative area of Kupang City.

3. The formation of a prediction model for motorcycle accident victims only takes into account the number of victims killed or seriously injured, excluding minor injuries.

4. The result of the correlation between accident and geometric roads are not considered by geometric standards.

\section{Literature review}

\subsection{General}

In recent years, highway experts have continued to develop an interest in predicting the number of accidents that may occur on a road segment. Much research has been done in this field by developing accident prediction models through statistical analyzes. The GLM

* Corresponding author: margiebolla@gmail.com 
(Generalized Linear Method) method has also been used in previous studies such as following:

1. Motorcycle Accidents Modelling in Surabaya City With The GLM Method [4].

From the results of the research that has been done, things can be concluded as following:

a. The motorcycle accident prediction model (MCA) produced is:

$\mathrm{MCA}=0.00003278$ Flow $^{3.369} \exp ^{[0.03561 \% \mathrm{MC}-0.1346}$ LaneWidth -0.588 JLane (1)]

b. Predicted model of motorcycle accident victims who died and major injured (KSI) are:

KSI $=0.000656$ Flow $^{3.092} \exp [0.629 \%$ MC (1) -0.2262 LaneWidth]

2. Motorcycle Accidents Modelling In The Road Of Atambua City [5].

After analyzing with the Genstat Release 9.2 program, the accident prediction model was obtained as follows:

MCA $=0.002902 \exp { }^{[-0,986 \text { LaneWidth-0.674 ShoulderWidth }+}$ 0.1761 Speed]

\subsection{Vehicle flow}

Flow is the number of vehicles passing a road in a certain time unit. Traffic flow is usually measured by placing a counter at the current place which wants to be known, or it can be done manually. Calculations can be made for vehicles that move in one direction or two directions. The general formula used to calculate traffic flow is [1]:

$$
Q=\frac{n}{T}
$$

Where :

$\mathrm{Q}:$ traffic flow (vhc/hr)

$n$ : number of vehicles (volume) that passes through the observation point in the time interval $\mathrm{T}$

$\mathrm{T}$ : observation time interval $(<1$ hour $)$

Traffic flows consist of various types of vehicles such as passenger vehicles, trucks, buses and motorcycles. In order to facilitate the calculation, the size of the traffic volume of various types of vehicles is stated in the Passenger Car Unit by multiplying certain factors or the Passenger Car Equivalent .

\subsection{Speed}

Speed is the ability of a vehicle to travel a certain distance per unit of time, speed is usually expressed in meters/seconds or kilometers/hour (kph). The basic equation for vehicle speed is[1]:

$$
V=\frac{L}{T}
$$

Where :

$\mathrm{V}$ : Average speed of space ( $\mathrm{km} /$ hour)

L: The distance traveled $(\mathrm{km})$

Q: Travel time of vehicles along L segment (hours)
This study uses 85-percentile in speed data processing. 85 -Percentile meaning a traffic speed where $85 \%$ of drivers drive their vehicles on the road without being affected by lower traffic speeds or bad weather.

\subsection{Generalized linear method (GLM)}

Generalized Linear Models (GLM) used for create a model which observation data (response variable) is not normally distributed. The general equation used in the GLM method is [6]:

$\mathrm{FK}=\mathrm{kX}_{1}{ }^{\alpha 1} \cdot \mathrm{X}_{2}{ }^{\alpha 2} \ldots \ldots . \exp ^{(\beta 1 \mathrm{Y} 1)} \cdot \exp ^{(\beta 2 \mathrm{Y} 2)} \ldots \ldots . \exp ^{(\beta \mathrm{nY})}$

Where :

FK = The frequency of traffic accidents that will be predicted

$\mathrm{Xi}, \mathrm{Yj}=$ explanatory variables $(\mathrm{i}=1,2,3, . . ; \mathrm{j}=1,2,3$. $)$

$\alpha, \beta=$ variable coefficient

\subsection{Stages of analysis of the GLM method}

Correlation test, used for determining the attachment of relationships between fellow explanatory variables, which are expressed with correlation coefficients. Fellow explanatory variables cannot be correlated with each other. The parameter value/correlation coefficient $(r)$ is: $>0.9$ - 1.0 means having a very strong relationship;

$>0.7-0.9$ means having a strong relationship;

$>0.5-0.7$ means having a moderate relationship;

$>0.3-0.5$ means having a weak relationship;

$>0,0$ - 0,3 means having a very weak relationship;

Negative or positive signs only indicate the character of relationship between variables. If positive, the otherwise. Two variables have a unidirectional relationship, and Univariate analysis, conducted to determine the effect of each explanatory variable individually, and at the same time check the level of significance of the response variable (number of motorcycle accidents). The initial description of the contribution of explanatory variables can be known from the results of this analysis.

Multivariate analysis, where the quantitative effects and significance of several explanatory variables together on the response variable will be examined. This is necessary because the cause of an accident is a combination of several factors.

\subsection{Stages of collecting data}

In this study, data collection was carried out using the survey method at the research location. The survey conducted was as follows:

1. Preliminary survey

Preliminary survey in the form of a traffic flow survey on the review road. The preliminary survey aims to determine the peak hour of the vehicle flow which will be used as the basis for determining the time of the next traffic survey.

2. Geometric Road Survey 
Geometric road survey aims to identify geometric elements of the road including the width of the road lane, the width of the road shoulder, the calculation of the number of access and the presence of the sidewalk.

3. Traffic Survey

This survey aims to obtain traffic flow data on roads and the proportion of motorbikes to the total traffic flow. The survey was conducted by calculating the number of vehicles classified according to vehicle type.

\section{Research Stages}

The steps taken are as follows:

1. Collect secondary data, such as Accident Data in Kupang City in 2011 until 2017 to recapitulate data as a basis for Accident Descriptive Analysis and to determine the road that will be used as the research location.

2. Determine response variables and explanatory variables in Accident Modelling.

3. Collecting primary data, such as traffic data and geometric data of the road, by conducting traffic surveys and geometric measurements of the road.

4. Analysing Accident Data with correlation tests to determine the attachment of the relationship between the response variables and explanatory variables and also among other explanatory variables, univariate tests used for determine the contribution of explanatory variables to individual response variables and multivariate tests used for determine the contribution of explanatory variables to the response variables simultaneously.

\section{Results And Discussion}

\subsection{Result of accident data descriptive analysis}

The characteristics of motorcycle accidents on the observed road are the number of accident victims based on gender, severity, type of work, level of education, type of crash, time of occurrence (day and range of hours), the proportion of age and ownership of Driving License (SIM) by the perpetrator and victim.

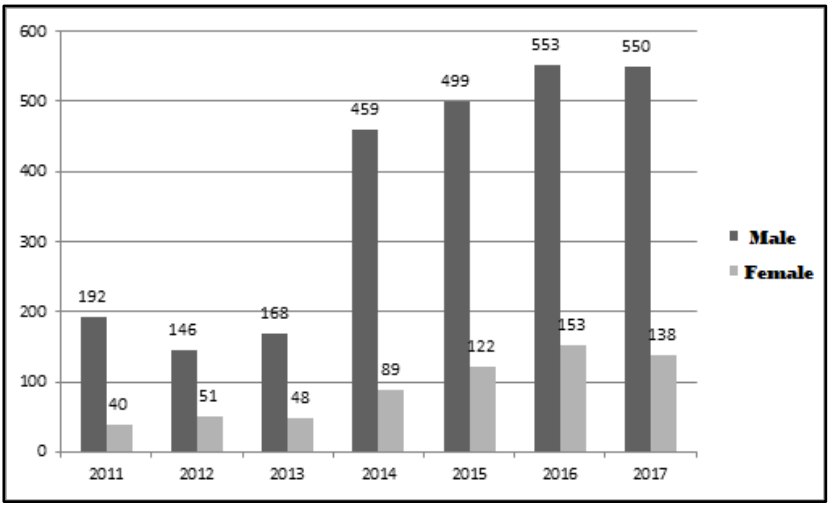

Fig. 1. Motorcycle accident victims based on gender
The diagram in Figure 1 shows that the average motorcycle accident between 2011 and 2017 is more common among male riders with a total of 2567 people $(80.02 \%)$. This can be caused by the number of male vehicle users are larger than female riders, so the risk of accidents experienced by male riders is greater than female riders.

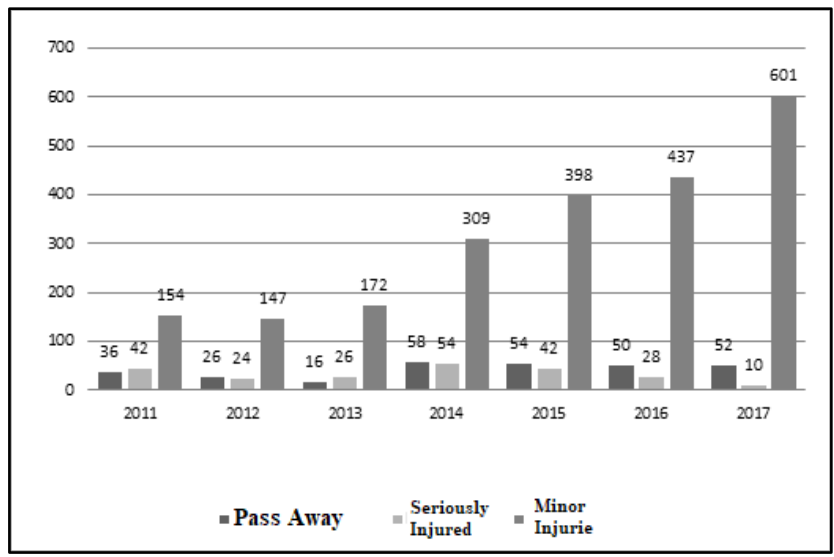

Fig. 2. Motorcycle accidents based on severity

Based on the graph in Figure 2, accident victims with the severity of minor injuries were the biggest $(81.07 \%)$ and the victims died due to accidents reached 292 people (10.67\%). The highest number of victims died in 2014, namely 58 people.

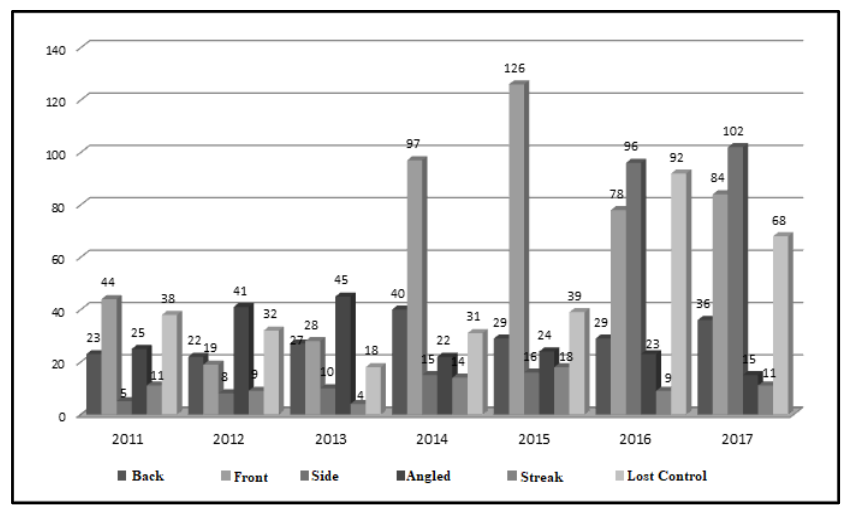

Fig. 3. Motorcycle accidents based on crash types

In Figure 3 it can be seen that the front crash type has a more dominant number than other types of crash. The highest front hit occurred in 2015 where there were 126 cases $(26.47 \%)$. This type of crash can be caused by the absence of a median of the road or is affected by the disorderly behavior of the driver.

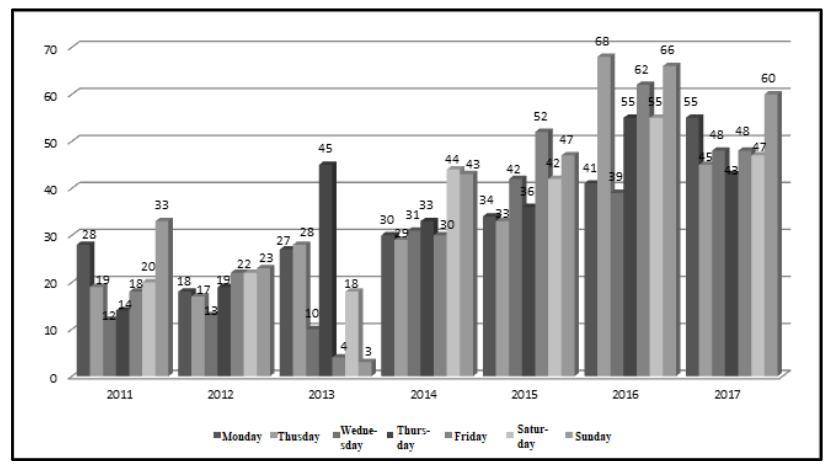


Fig. 4. Motorcycle accidents based on day of incident

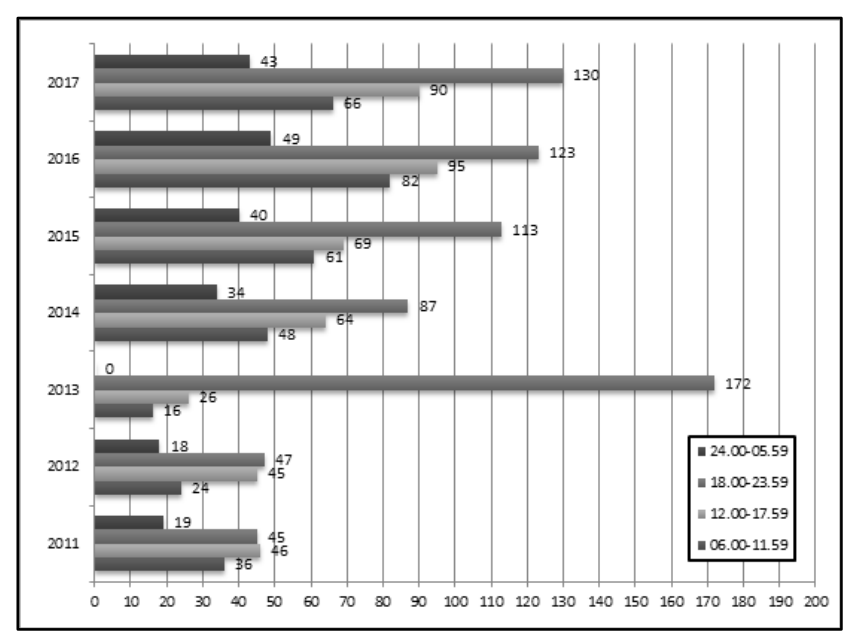

Fig. 5. Motorcycle accidents based on the event time range

Based on the graph in Figure 4, accidents occur most often on Sundays (16.45\%). Whereas for the hours range category, based on Figure 5, accidents most often occur in the afternoon to night with time intervals between 6:00 p.m. and 11:59 p.m. (42.48\%). The highest number of accidents at the time interval between 18:00 to 23:59 WITA occurred in 2013, namely 172 cases $(23.99 \%)$. This can be caused by the fact that during this time the road flow conditions are more flexible so that undisciplined motorists tend to drive vehicles at high speeds which increases the risk of accidents. Another factor that can also be a cause is at these times driver is susceptible to being in an unfit condition such as exhaustion or drowsiness.

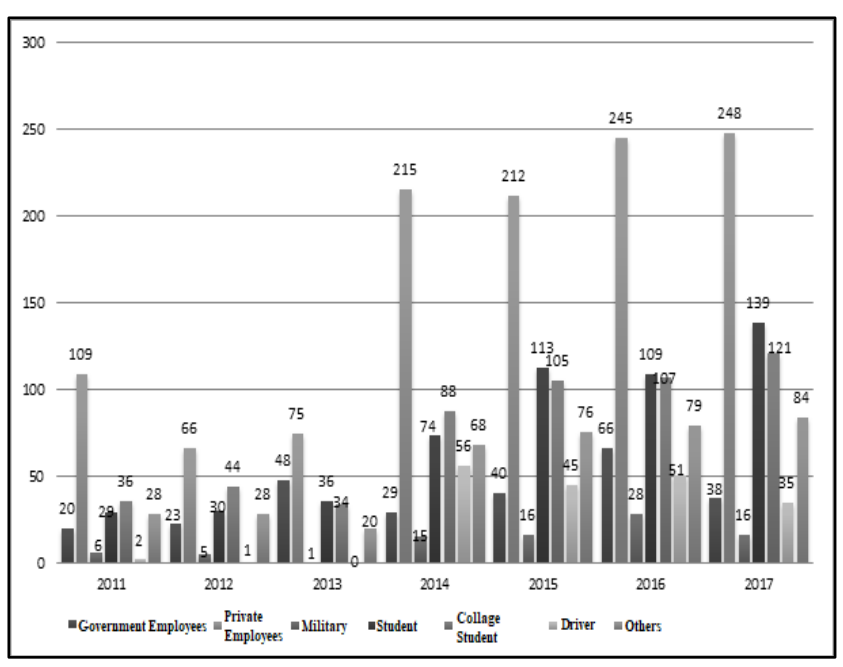

Fig. 6. Motorcycle accidents based on type of work

The relationship between the level of motorcycle accidents and the type of work is shown in Figure 6 where most of the drivers who had accidents worked in the private sector $(37.04 \%)$. The highest number of private professions that experienced accidents occurred in 2017 , which amounted to 248 people $(21.20 \%)$. This can be affected by higher mobility of private workers compared to motorists who have non-private jobs.

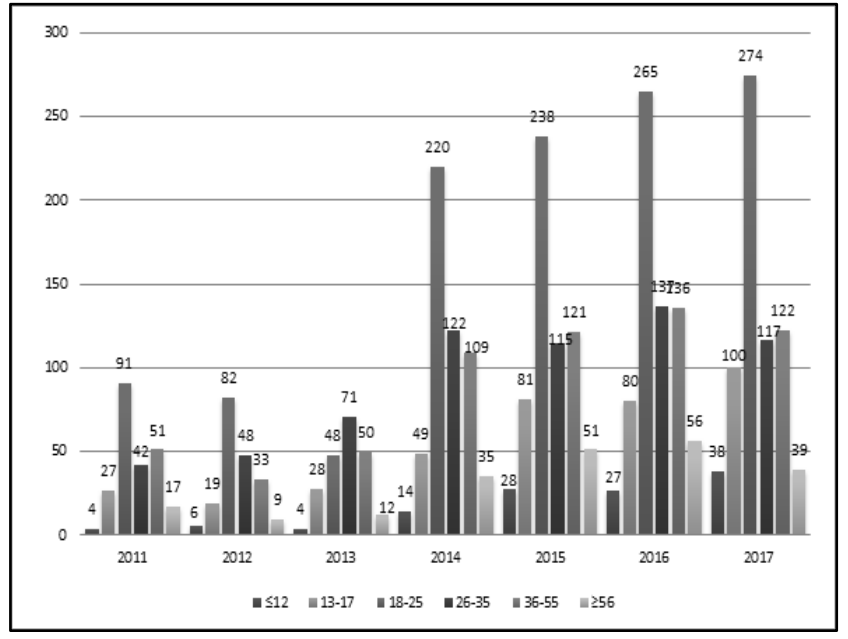

Fig.7. Motorcycle accidents based on age proportion

Based on the diagram in Figure 7 it can be seen that the age most frequently involved in accidents is the age range of $18-25$ years $(37.87 \%)$. This can be caused by the fact that most motor vehicle users are in that age range, so the likelihood of accidents at that age range is the biggest and also the relatively young age factor can effect unstable emotions and disorderly driving behavior. The highest number of accidents in the age range of 18-25 occurred in 2017 , as many as 274 people $(22.50 \%)$.

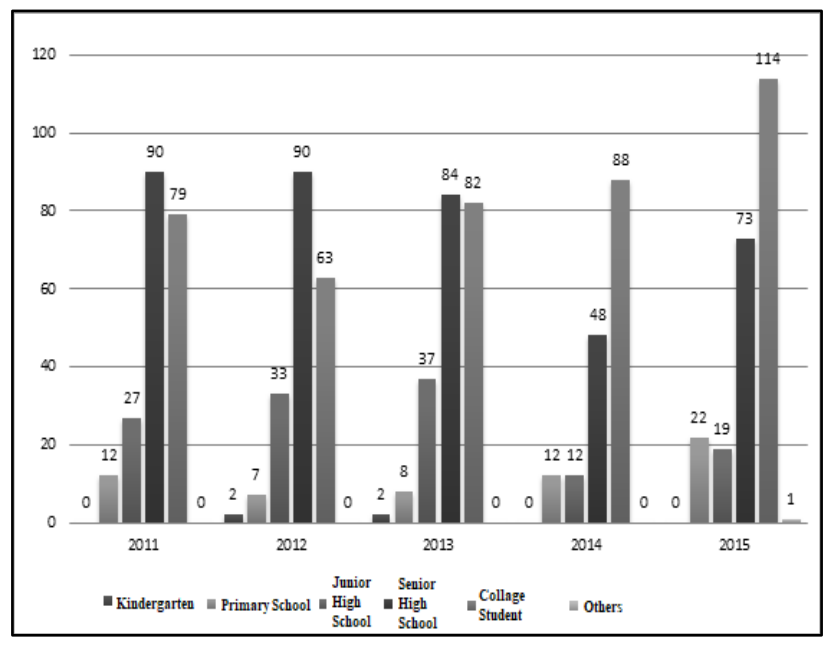

Fig. 8. Motorcycle accidents based on education level

Based on the diagram in Figure 8 it can be seen that the drivers who are most often involved in accidents are motorists with College education level $(42.39 \%)$. The highest number of accident victims with College education levels occurred in 2015, as many as 114 people $(26.76 \%)$. This can be caused by the number of motorcycle riders in Kupang dominated by college students scattered in various areas of Kupang City so that the risk of accidents on motorists with this level of education is greater than motorists with other levels of education. 


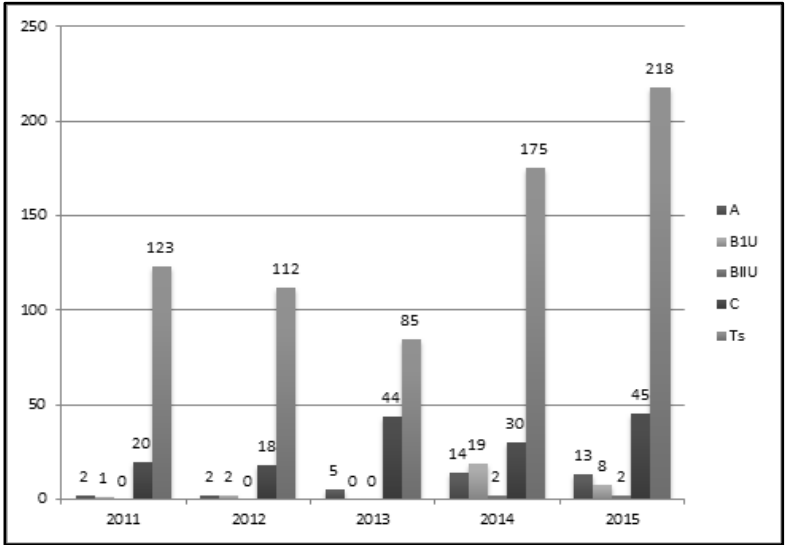

Fig. 9. Motorcycle accidents based on driver's license (SIM)

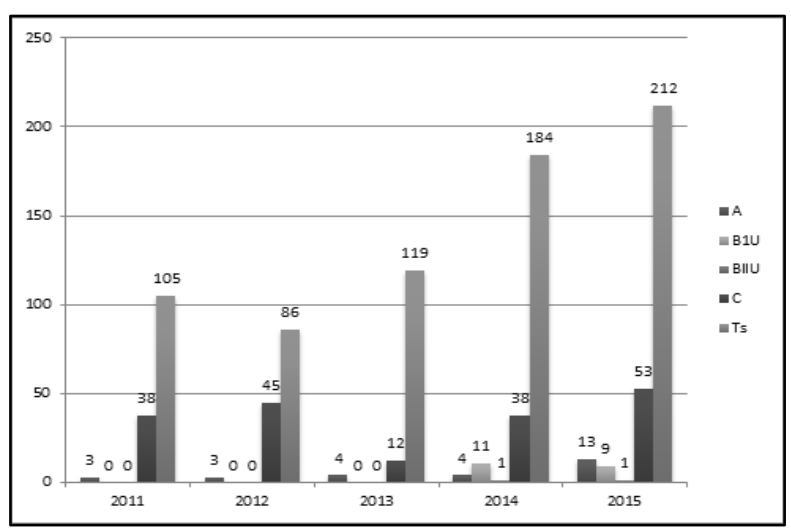

Fig. 10. Motorcycle accidents based on victim's license (SIM)

Figure 9 and Figure 10 explain that most of the perpetrators and victims involved in a motorcycle accident did not have a license (SIM) (75.43\%). The highest number occurred in 2015, namely 218 perpetrators $(30.57 \%)$ and 212 victims $(30.02 \%)$ who did not have a license. This can be affected by the lack of knowledge regarding traffic safety or irregular driving behavior.

\subsection{Results of accident data recapitulation}

Table 1 shows the recapitulation of motorcycle accidents and ownership of driving license (SIM) from 2011 to 2017 on the observed road section

Table 1. Motorcycle accident recapitulation on the observed

\begin{tabular}{|c|l|c|c|c|}
\hline No. & Road Name & $\begin{array}{c}\text { Number } \\
\text { of } \\
\text { Accident }\end{array}$ & $\begin{array}{c}\text { With } \\
\text { License } \\
\text { (SIM) }\end{array}$ & $\begin{array}{c}\text { Without } \\
\text { License } \\
\text { (SIM) }\end{array}$ \\
\hline 1 & Adisucipto & 38 & 8 & 30 \\
\hline 2 & Piet A. Tallo & 42 & 10 & 32 \\
\hline 3 & Frans Seda & 76 & 23 & 53 \\
\hline 4 & Eltari & 30 & 8 & 22 \\
\hline 5 & Timor Raya & 258 & 74 & 184 \\
\hline 6 & Ahmad Yani & 21 & 3 & 18 \\
\hline 7 & Soekarno & 8 & 5 & 3 \\
\hline 8 & Siliwangi & 2 & 2 & 0 \\
\hline 9 & Pahlawan & 49 & 12 & 37 \\
\hline 10 & Yos Sudarso & 18 & 6 & 12 \\
\hline
\end{tabular}

\subsection{Geometric and traffic survey results on reviewed roads}

The survey is carried out for 10 (ten) days ( 5 working days and 5 weekend days). Table 2 shows the recapitulation of the results of the geometric survey and traffic on the road section that observed.

Table 2. Results of accident data recapitulation, geometric survey and traffic survey on the observed road section

\begin{tabular}{|c|c|c|c|c|c|c|c|c|c|c|}
\hline No & Road Name & $\begin{array}{c}\text { Lenght } \\
\text { of Road } \\
(\mathrm{m})\end{array}$ & $\begin{array}{c}\text { Total } \\
\text { Lane } \\
\text { Width } \\
(\mathrm{m})\end{array}$ & $\begin{array}{c}\text { Shoul } \\
\text { der } \\
\text { width } \\
(\mathrm{m})\end{array}$ & $\begin{array}{c}\text { Sider } \\
\text { alk } \\
\text { width } \\
(\mathrm{m})\end{array}$ & $\begin{array}{c}\text { Flow } \\
\mathbf{2}\end{array}$ & $\begin{array}{c}\mathbf{8 5} \\
\text { (smp/hr } \\
\text { ) }\end{array}$ & $\begin{array}{c}\text { Percenti } \\
\text { le } \\
\text { Speed } \\
\text { (km/hr) }\end{array}$ & $\begin{array}{c}\text { Percent } \\
\text { age of } \\
\text { motorc } \\
\text { ycles } \\
(\%)\end{array}$ & $\begin{array}{c}\text { Total } \\
\text { Road } \\
\text { Access }\end{array}$ \\
\hline 1 & Adisucipto & 4750 & 12,00 & 1,55 & 1,50 & 1 & 1740,47 & 49,04 & 50,25 & 28 \\
\hline 2 & Piet A. Tallo & 5100 & 14,30 & 1,90 & - & 1 & 3966,68 & 49,79 & 50,24 & 23 \\
\hline 3 & Frans Seda & 5850 & 17,20 & 2 & 1,50 & 1 & 3666,85 & 49,81 & 44,79 & 45 \\
\hline 4 & Eltari & 3200 & 21,00 & 0 & 2,23 & 1 & 3650,76 & 51,85 & 48,22 & 13 \\
\hline 5 & Timor Raya & 12580 & 11,00 & 2,25 & - & 0 & 2612,44 & 50,78 & 46,18 & 80 \\
\hline 6 & Ahmad Yani & 1150 & 11,00 & - & 1,80 & 0 & 2538,15 & 45,38 & 44,81 & 13 \\
\hline 7 & Soekarno & 600 & 8,40 & - & 1,55 & 0 & 2272,26 & 41,16 & 46,49 & 15 \\
\hline 8 & Siliwangi & 550 & 6,60 & - & 1,10 & 0 & 1512,08 & 43,04 & 27,76 & 8 \\
\hline 9 & Pahlawan & 2500 & 8,20 & 2,00 & - & 0 & 2297,17 & 47,49 & 56,59 & 13 \\
\hline 10 & Yos Sudarso & 9200 & 6,20 & 2,50 & - & 0 & 1211,35 & 41,16 & 59,70 & 14 \\
\hline
\end{tabular}

\subsection{Correlation test}

Correlation test, was conducted to determine the attachment of relationships between fellow explanatory variables, which are expressed with correlation coefficients. Based on the correlation test results in Table 3 there is a weak correlation between the variables Shoulder width/Sidewalk, variable speed and License/without License variables on the number of Motorcycle Accidents (MCA) with correlation coefficients of $-0.484,0.514$ and -0.387 . While the variables that correlate very weakly to the number of motorcycle accidents are variable width with a correlation coefficient of 0.117 , a median variable with a correlation coefficient of -0.089 , a current variable with a correlation coefficient of 0.193 , a proportion of motorcycle variables (\% motor) with a correlation coefficient of 0.044 and a variable number of access per kilometer of road with correlation coefficient -0.27 .

Table 3. Motorcycle accident model correlation matrix (MCA)

\begin{tabular}{|c|c|c|c|c|c|c|c|c|c|}
\hline MCA & 1.000 & & & & & & & & \\
\hline Lane width & 0.117 & 1.000 & & & & & & & \\
\hline $\begin{array}{l}\text { Shoulder/ } \\
\text { Sidewalk }\end{array}$ & -0.448 & 0.029 & 1.000 & & & & & & \\
\hline Median & -0.089 & 0.820 & -0.250 & 1.000 & & & & & \\
\hline Flow & 0.193 & 0.841 & -0.048 & 0.642 & 1.000 & & & & \\
\hline Speed & 0.514 & 0.797 & -0.342 & 0.682 & 0.714 & 1.000 & & & \\
\hline $\begin{array}{c}\% \\
\text { Motorcycle }\end{array}$ & 0.044 & 0.021 & -0.574 & 0.088 & 0.021 & 0.084 & 1.000 & & \\
\hline Access & -0.274 & 0.321 & 0.636 & -0.372 & 0.177 & 0.558 & -0.530 & 1.000 & \\
\hline $\begin{array}{l}\text { License/ } \\
\text { Without } \\
\text { License }\end{array}$ & -0.347 & 0.453 & 0.612 & -0.408 & 0.363 & 0.638 & -0.642 & 0.872 & 1.000 \\
\hline & MCA & $\begin{array}{l}\text { Lane } \\
\text { width }\end{array}$ & $\begin{array}{c}\text { Shoulder } \\
\text { width/ } \\
\text { Sidewalk }\end{array}$ & Median & Flow & Speed & $\begin{array}{c}\% \\
\text { Motorcycle }\end{array}$ & Access & $\begin{array}{l}\text { License/ } \\
\text { Without } \\
\text { License }\end{array}$ \\
\hline
\end{tabular}

\subsection{Univariate test}

The Univariate Test is a test carried out on individual explanatory variables on the response variable. The aim of Univariate analysis is to find out individual explanatory contributions to response variables. Only variables that 
are significant variables will then be included in the multivariate analysis.

Table 4. Results of univariate analysis of motorcycle accident models

\begin{tabular}{|c|c|c|c|c|}
\hline $\begin{array}{c}\text { Explanatory } \\
\text { Variables }\end{array}$ & $\begin{array}{c}\text { Estimation } \\
\text { Coefficient }\end{array}$ & $\begin{array}{c}\text { Standar } \\
\text { Error }\end{array}$ & $t$-value & $\begin{array}{c}\text { Significant } \\
\text { on } \alpha=0.05\end{array}$ \\
\hline $\begin{array}{c}\text { Constant } \\
\text { Lane width }\end{array}$ & 0,03226 & 0,0907 & 3,56 & $<0,001$ \\
\hline $\begin{array}{c}\text { Constant } \\
\text { Shoulder/ }\end{array}$ & 4,3841 & 0,0455 & 96,26 & $<0,001$ \\
Sidewalk & $-1,660$ & 0,136 & 12,21 & $<0,001$ \\
\hline $\begin{array}{c}\text { Constant } \\
\text { Median }\end{array}$ & 4,0832 & 0,0530 & 77,06 & $<0,001$ \\
\hline Constant & 3,258 & 0,138 & 23,59 & $<0,001$ \\
Flow & 0,0002763 & 0,0000473 & 5,84 & $<0,001$ \\
\hline $\begin{array}{c}\text { Constant } \\
\text { Speed }\end{array}$ & $-7,982$ & 0,856 & $-9,32$ & $<0,001$ \\
\hline Constant & 0,2474 & 0,0173 & 14,32 & $<0,001$ \\
Motorcycle & 3,641 & 0,265 & 13,75 & $<0,001$ \\
\hline Constant & 4,5921 & 0,0769 & 59,74 & $<0,001$ \\
Access & $-0,0812$ & 0,0100 & $-8,11$ & $<0,001$ \\
\hline Constant & 4,1972 & 0,0433 & 96,96 & $<0,001$ \\
License/ & $-2,588$ & 0,319 & $-8,11$ & $<0,001$ \\
Without & & 0,00545 & 1,35 & 0,176 \\
License & & & & \\
\hline
\end{tabular}

Based on Table 4, it can be seen that the variables that fulfill the significance value are Variable Lane, Street Shoulder, Sidewalk, Median, Flow, Speed, Access, License and without License while the variable \% Motorcycle does not fulfill the significance requirement so it is not included in the Multivariate test.

\subsection{Multivariate test}

Multivariate analysis was conducted to determine the quantitative effects of explanatory variables simultaneously on the response variable.

Table 5. Results of multivariate analysis of motorcycle accident models

\begin{tabular}{|l|l|l|l|l|l|}
\hline Parameter & estimate & s.e. & $\mathrm{t}(*)$ & $\mathrm{t}$ pr. & antilog of \\
\cline { 6 - 7 } & & & & estimate \\
\hline Constant & -7.31 & 1.48 & -4.95 & $<.001$ & 0.0006713 \\
\hline Lane width & 0.2144 & 0.0484 & 4.43 & $<.001$ & 1.239 \\
\hline $\begin{array}{l}\text { Shoulder } \\
\text { width/ } \\
\text { Sidewalk }\end{array}$ & -1.952 & 0.220 & -8.87 & $<.001$ & 0.1420 \\
\hline Median & -2.026 & 0.229 & -8.86 & $<.001$ & 0.1318 \\
\hline Flow & 0.000275 & 0.000126 & -2.19 & 0.029 & 0.9997 \\
\hline Speed & 0.2139 & 0.0348 & 6.15 & $<.001$ & 1.239 \\
\hline Access & 0.0513 & 0.0181 & 2.83 & 0.005 & 1.053 \\
\hline
\end{tabular}

Based on the data in Table 5, the variable Width Lane with a coefficient value of 0.001 , the variable Shoulder and Sidewalk Presence with a coefficient of 0.001 , median variable with a coefficient of 0.001 , a current variable with a coefficient of 0.029 , a variable speed with a coefficient of 0.001 , and an access variable with coefficient value 0.005 has fulfilled the significance requirement smaller than 0.05 so that it can be included in the modelling results.

\subsection{Modelling results}

The results of multivariate analysis with the GLM method, obtained the final model for the prediction of motorcycle accidents in the city of Kupang are as follows.

$\mathrm{MCA}=0,0006713(0,000275$ Flow $) \exp [$ [0,2144 LaneWidth - 1,952

ShoulderWidth_Sidewalk - 2,026 MedianRoad + 0,2139 Speed + 0,0513 Access]

where:

MCA : Number of Motorcycle Accidents

Lane width : Total Width of Road Lanes (m)

Shoulder/Sidewalk: Existence of Road Shoulder (m) and

Sidewalk $(\mathrm{m})$

Median : Existence of Median Road

Flow : Traffic flow (smp / hour)

Speed : $85 \%$ percentile of vehicle speed accumulation (km / hour)

Access : Number of Access Per Km of Road

\subsection{Model limitation}

Modelling generally has limitations related to the suitability of the model with the characteristics of the existing location. This needs attention for all parties who will use a model on the location (sample) with different characteristics than when the model was made. The model formed in this study is suitable for traffic characteristics and geometric elements of the road segments as follows: The total range of lane width : 6.2 - 21 meters

Shoulder width range : $0-2.25$ meters

Sidewalk Width Range : $0-2.23$ meters

Traffic flow range: 1121.35 - $3966.68 \mathrm{pcu} /$ hour

Vehicle speed : 41.16 - $51.85 \mathrm{~km} / \mathrm{h}$ (85-percentile Speed)

Percentage of motorbikes : $27.76 \%-59.7 \%$

Amount of Access per Km: 2 - 25 access roads

\subsection{Result of accident model interpretation}

Based on the results of modelling using the Genstat program there are several variables that affect the number of motorcycle accidents on arterial roads in Kupang City. These variables can increase and reduce the percentage of motorcycle accidents on the road segments studied. The influence of each variable on the number of accidents can be explained as follows.

$>$ Effect of Total Lane Width

For road segments $<11$ meters, the addition of a lane width of $1.0 \mathrm{~m}$ is predicted to reduce the number of motorcycle accidents by $10 \%$ per year.

$>$ Effect of Shoulder/Sidewalk Presence

For each existence of road shoulder elements and sidewalk elements on a road segment can reduce the number of motorcycle accidents by $6 \%$ per year.

$>$ Effect of Median Road Existence

For each median element presence on a road segment can reduce the number of motorcycle accidents by $13 \%$ per year.

$>$ Effect of Vehicle Traffic Flow

For every $10 \%$ increase in total flows on a road can increase the number of motorcycle accidents by $3 \%$ per year. 
Effect of Vehicle Speed

Adding a speed of $10 \%$ is predicted to increase the number of accidents by $14 \%$.

$>$ Effect of Amount of Access per Kilometer of Road The addition of 1 road access on a road segment is predicted to increase the number of accidents by $2 \%$.

\subsection{Action recommendations}

a. For the Government and Related Services

> It is necessary to add the median road element on the road that does not have a road median and also the addition of a sidewalk element for each road section that only has road shoulder elements, so the accident rate with the front hit and pedestrian hit types can be reduced.

$>$ It is necessary to place a tape on the point before the level crossing, before school, or places that are dangerous when walking too fast to reduce the speed of the vehicle.

$>$ It is necessary to place related traffic signs such as signs for speed limits and caution signs on roads with the number of access roads so that road users are alerted and the risk of collisions between motorists on the main road with drivers heading to the main road can be reduced .

b. For the Police of Kupang City Traffic Unit

$>$ It is necessary to increase the selectivity of theoretical exams and ownership of licenses for motorcycle control, especially for those who are underage.

> Need to socialize safety driving (safety ridding) so as to increase awareness of motorcycle riders.

$>$ Need to do sweeping for drivers who do not have a license (SIM)

\section{Conclusion}

Based on Data Analysis and Discussion, the conclusions obtained are as follows.

1. Characteristics of Motorcycle Accidents in Kupang City

$>$ The most frequent accidents occur on Sundays $(15.95 \%)$; the span of time between 6:00 p.m. $11: 59$ p.m. WITA (45.94\%); front hit type (35.68\%); death toll (12.19\%).

$>$ Accidents most often occur in drivers of male sex $(80.71 \%)$; age range $18-25$ years $(37.20 \%)$; with education level at the University level (42.38\%); working in the private sector (37.75\%); does not have a Driving License (75.43\%).

2. Geometric factors and traffic factors have a significant effect on the number of motorcycle accidents on arterial roads in Kupang City.

3. Motorcycle Accident Prediction Model

After analyzing with the help of the GenStat 9th Edition program, the following accident prediction models were obtained:

MCA $=0,0006713(0,000275$ Flow $)$ exp [0.2144 Lane Width 1,952 ShoulderWidth_Sidewalk-2,026 MedianRoad + 0,2139 Speed + 0,0513 Access]
Referring to the model obtained, it can be interpreted that the effect of each variable on the number of accidents is as follows:

$>$ The total lane width increase of $1.0 \mathrm{~m}$ on the road segment with a total lane width of $<11$ meters is predicted to reduce the number of motorcycle accidents by $10 \%$ per year.

$>$ The existence of sidewalk and road shoulder elements on a road segment can reduce the number of motorcycle accidents by $6 \%$ per year.

$>$ The presence of median elements on a road segment can reduce the number of motorcycle accidents by $13 \%$ per year.

$>$ An increase in traffic of $10 \%$ can increase the number of motorcycle accidents by $3 \%$ per year.

$>$ An additional speed of $10 \%$ is predicted to increase the number of accidents by $14 \%$ per year.

$>$ The addition of the number of access per kilometer road segment is predicted to increase the number of accidents by $2 \%$ per year.

4. Program Action Recommendations

> It is necessary to add the median road element on the road that does not have a road median and also the addition of a sidewalk element for each road section that only has road shoulder elements, so the accident rate with the front hit and pedestrian hit types can be reduced.

$>$ It is necessary to place a tape on the point before the level crossing, before school, or places that are dangerous when walking too fast to reduce the speed of the vehicle.

$>$ It is necessary to place related traffic signs such as signs for speed limits and caution signs on roads with the number of access roads so that road users are alerted and the risk of collisions between motorists on the main road with drivers heading to the main road can be reduced.

\section{References}

1. Anonim, Manual Kapasitas Jalan Indonesia. Direktorat Jenderal Bina Marga, Departemen Pekerjaan Umum, (1997)

2. Satuan Lalu Lintas (SATLANTAS) Kota Kupang, Jumlah Kecelakaan, Koban Mati, Luka Berat, Luka Ringan, dan Kerugian Materi yang Diderita Tahun 2001-2017, (2017)

3. M.E. Bolla, Pemodelan Kecelakaan Sepeda Motor Di Kota Surabaya Dengan Metode GLM (Generalized Linear Model), Jurnal Universitas Nusa Cendana. Kupang (2012)

4. M.E. Bolla, T.M. Sir, and C.N. Bara, Pemodelan Kecelakaan Sepeda Motor Pada Ruas Jalan Kota Atambua, Jurnal Universitas Nusa Cendana. Kupang (2014)

5. M. Taylor, J.V. Kennedy, and A. Baruya, The Relationship Between Speed and Accidents on Rural Single-Carriageway Roads, Report TRL 511. Crowthorne, UK (2002) 